DOI: https://doi.org/10.24127/ajpm.v10i2.3635

\title{
PENGARUH PEMBELAJARAN DARING DENGAN GOOGLE CLASSROOM DAN GOOGLE MEET TERHADAP MINAT BELAJAR MATEMATIKA DISKRIT
}

\author{
Lilia Sinta Wahyuniar ${ }^{1 *}$, Siti Rochana ${ }^{2}$, Umi Mahdiyah $^{3}$, Niska Shofia ${ }^{4}$, \\ Suryo Widodo ${ }^{5}$ \\ 1,2,3,4,5 Universitas Nusantara PGRI Kediri, Kediri, Jawa Timur \\ *Corresponding author. \\ E-mail: $\quad$ liliasinta@unpkediri.ac.id ${ }^{\left.{ }^{*}\right)}$ \\ sitirochana@unpkediri.ac.id ${ }^{2)}$ \\ umimahdiyah@unpkediri.ac.id ${ }^{3)}$ \\ niskashofia@unpkediri.ac.id ${ }^{4)}$ \\ suryowidodo@unpkediri.ac.id ${ }^{5)}$
}

Received 22 March 2021; Received in revised form 23 June 2021; Accepted 06 July 2021

\begin{abstract}
Abstrak
Tujuan dari penelitian ini adalah untuk mengetahui pegaruh pembelajaran daring dengan google classroom dan pengaruh pembelajaran darng dengan google meet terhadap minat belajar mahasiswa pada mata kuliah matematika diskrit serta untuk mengetahui pengaruh pembelajaran daring dengan google clasroom dan google meet secara bersama-sama terhadap minat belajar matematika diskrit. Metode penelitian yang digunakan adalah kuantitatif. Teknik pengambilan sampel pada penelitian ini adalah menggunakan Simple Random Sampling. Pengambilan data pada penelitian ini menggunakan angket/kuisioner dengan menggunakan skala likert 1 sampai 4. Variabel pada penelitian ini terdiri dari variabel bebas dan variabel terikat. Variabel bebas terdiri dari 2 variabel yaitu variabel pertama pembelajaran daring dengan google classroom $\left(\mathrm{X}_{1}\right)$ dengan 3 indikator, variabel kedua pembelajaran daring dengan google meet $\left(\mathrm{X}_{2}\right)$ dengan 4 indikator. Variabel terikat dari penelitian ini adalah minat belajar (Y) dengan 4 indikator. Hasil dari penelitian ini adalah pembelajaran daring dengan google classroom memberikan pengaruh positif sebesar 1,354 terhadap minat belajar matematika diskrit, pembelajaran daring dengan google meet memberikan pengaruh sebesar -0,540 terhadap minat belajar matematika diskrit. Pembelajaran daring dengan google classroom dan pembelajaran daring dengan google meet secara bersama-sama mempunyai pengaruh sebesar 55\% terhadap minat belajar matematika diskrit, sedangkan sisanya $45 \%$ dipengaruhi oleh variabel di luar penelitian ini.
\end{abstract}

Kata Kunci: Google classroom; google meet; minat belajar matematika diskrit.

\begin{abstract}
The purpose of this study was to determine the effect of online learning with Google Classroom and the effect of online learning with Google Meet on student interest in learning in discrete mathematics courses and to determine the effect of online learning with Google Classroom and Google Meet together on interest in learning discrete mathematics. The research method used is quantitative. The sampling technique in this study was using Simple Random Sampling. Collecting data in this study using a questionnaire/questionnaire using a Likert scale of 1 to 4 . The variables in this study consisted of independent variables and dependent variables. The independent variable consists of 2 variables, the first variable is online learning with google classroom (X1) with 3 indicators, the second variable is online learning with google meet (X2) with 4 indicators. The dependent variable of this study is interest in learning $(Y)$ with 4 indicators. The results of this study are online learning with google classroom has a positive effect of 1.354 on interest in learning discrete mathematics, online learning with google meet has an effect of -0.540 on interest in learning discrete mathematics. Online learning with google classroom and online learning with google meet together have an influence of $55 \%$ on interest in learning discrete mathematics, while the remaining $45 \%$ is influenced by variables outside this study.
\end{abstract}

Keywords: Google classroom; google meet; interest in learning discrete mathematics.

This is an open access article under the Creative Commons Attribution 4.0 International License 
DOI: https://doi.org/10.24127/ajpm.v10i2.3635

\section{PENDAHULUAN}

Pada masa pandemi sekarang ini, seluruh sekolah dan universitas tidak diperbolehkan melakukan pembelajaran tatap muka. Berdasarkan hal tersebut, sekolah dan universitas menerapkan model pembelajaran daring atau pembelajaran online. Tujuan pembelajaran daring ini adalah agar mahasiswa maupun siswa bisa tetap belajar dan menuntut ilmu agar tidak ketinggalan materi. Selain itu, pembelajaran daring diharapkan dapat memudahkan guru atau dosen untuk memberikan materi sesuai dengan RPS yang sudah dibuat. (Yanti et al., 2020) Pembelajaran daring adalah pemanfaa-tan intenet dalam melakukan proses belajar mengajar yang sesuai dan efisien. Pembelajaran daring mengharuskan mahasiswa untuk tetap belajar sesuai jadwal yang sudah ditentukan (Muhammad, 2020).

Pembelajaran daring dapat menggunakan berbagai aplikasi tetapi yang umum dan sering digunakan adalah Google Classroom dan Google Meet, karena Google classroom dan Google Meet merupakan aplikasi yang mudah dioperasikan dan menarik bagi para mahasiswa maupun dosen. Sehingga pada masa pandemi seperti sekarang ini, minat belajar mahasiswa dapat meningkat dengan adanya media pembelajaran daring atau aplikasi google meet dan google classroom.

Google classroom merupakan inovasi yang paling menarik yang dapat digunakan pendidik dan peserta didik dalam melaksanakan pembelajaran. (Rahmanto \& Bunyamin, 2020). Hal lain juga diungkapkan bahwa dengan google meet, siswa dapat berinteraksi, menghasilkan suasana belajar yang mengasyikan dan mendorong siswa untuk aktif dalam pembelajaran sehingga menaikkan hasil belajar siswa. (Muhati et al., 2021).
Indikator dari pembelajaran daring dengan google classroom adalah terdiri dari empat indikator yaitu respon mahasiswa dalam kemudahan mengakses aplikasi google classroom, pemahaman materi dalam pembelajaran dengan menggunakan google classroom, keefektifan penggunaan aplikasi google classroom dalam pembelajaran daring, penggunaan google classroom dalam mengajar. (Suhada et al., 2020). Indikator dari angket yang diberikan pada mahasiswa terdiri dari 4 indikator yaitu respon mahasiswa dalam mengakses aplikasi google meet, pemahaman mahasiswa terhadap materi dalam pembelajaran dengan menggunakan google meet, keefektifan aplikasi google meet dalam pembelajaran daring, penggunaan google meet dalam pembelajaran. (Wiratama, 2020).

Menurut (Lestari, 2014) minat belajar merupakan dorongan dari dalam diri seorang siswa untuk meningkatkan kebiasaan belajar. Menurut (Friantini \& Winata, 2019) ada 4 indikator minat belajar yaitu adanya perasaan senang terhadap pembelajaran, adanya pemusatan perhatian dan pikiran terhadap pembelajaran, adanya kemauan untuk belajar, adanya kemauan dari dalam diri untuk aktif dalam pembelajaran.

Penelitian yang pernah dilakukan oleh (Sijabat et al., 2020) memperoleh hasil bahwa terdapat pengaruh pembelajaran daring terhadap minat belajar fisika umum. Hasil yang didapat dari penelitian (Kurniawan, 2021) adalah pengaruh metode pembelajaran daring terhadap minat belajar mahasiswa sebesar 3,8\%. Sedangkan penelitian yang dilakukan oleh (Jusmawati et al., 2020) memperoleh hasil yaitu terdapat pengaruh pembelajaran berbasis daring terhadap 
minat belajar matematika. Sejalan dengan penelitian sebelumnya, bahwa penelitian yang dilakukan oleh (Yunitasari \& Hanifah, 2020) memperoleh hasil yaitu pembelajaran daring pada masa pandemi COVID-19 sangat berpengaruh terhadap minat belajar siswa.

Dari beberapa penelitian terdahulu terlihat bahwa pembelajaran daring mempunyai pengaruh terhadap minat belajar dan penelitian terdahulu hanya menggunakan variabel pembelajaran daring saja tanpa menyebutkan aplikasi daring yang digunakan. Sedangkan dalam penelitian ini, menyebutkan variabel pembelajaran daring dengan menggunakan google classroom dan google meet terhadap minat belajar matematika diskrit.

Mata kuliah matematika diskrit merupakan mata kuliah yang perlu penjelasan secara detail (tidak hanya materi tertulis saja yang diberikan tetapi perlu juga penjelasan tentang materi tersebut). Mata kuliah matematika diskrit merupakan mata kuliah yang wajib ditempuh mahasiswa tingkat satu program studi Teknik Informatika. Perkuliahan secara daring untuk matematika diskrit di sini menggunakan google classroom dan google meet. Di dalam google classroom tersebut, dosen dapat memberikan materi tertulis dalam bentuk pdf dan ada juga video penjelasan mengenai materi yang diberikan tujuannya adalah agar mahasiswa bisa lebih mudah memahami materi-materi yang ada pada mata kuliah matematika diskrit dan diharapkan agar mahasiswa juga tetap mempunyai minat untuk belajar matematika. Sedangkan dalam google meet, dosen memberikan penjelasan langsung tentang materi pada matematika diskrit.
Tujuan penelitian ini adalah 1) untuk mengetahui pengaruh pembelajaran daring dengan google classroom terhadap minat belajar mahasiswa pada matematika diskrit; 2) untuk mengetahui pengaruh pembelajaran daring dengan google meet terhadap minat belajar mahasiswa pada matematika diskrit dan 3) untuk mengetahui pengaruh pembelajaran daring dengan google classroom dan google meet secara bersama-sama terhadap minat belajar mahasiswa pada matematika diskrit.

\section{METODE PENELITIAN}

Penelitian ini termasuk jenis penelitian kuantitatif yaitu penelitian dengan mengumpulkan data yang dapat diukur menggunakan teknik statistik untuk mengetahui pengaruh model pembelajaran daring terhadap minat belajar matematika diskrit. Data kuantitatif pada penelitian ini adalah angket/kuisioner tertutup yang diberikan kepada mahasiswa.

Penelitian ini dilakukan dengan menerapkan pembelajaran daring dengan google classroom dan google meet pada mata kuliah matematika diskrit di program studi Teknik Informatika kelas 1A, 1B dan 1C. Pada saat perkuliahan, dilakukan observasi tentang model pembelajaran daring dengan google classroom dan google meet. Kemudian, memberikan angket tertutup kepada sejumlah mahasiswa yang dijadikan sampel untuk mengetahui pengaruh google classroom dan google meet terhadap minat belajar matematika diskrit.

Subjek dalam penelitian ini adalah Mahasiswa Tingkat 1 Teknik Informatika Universitas Nusantara PGRI Kediri. Lokasi penelitian di Fakultas Teknik Kampus 2 Universitas PGRI Kediri Mojoroto Gang 1 No.6 
Kota Kediri. Populasi yang digunakan dalam penelitian ini sebanyak 118 mahasiswa semester satu dari 3 kelas program studi Teknik Informatika Universitas Nusantara PGRI Kediri. Teknik pengambilan sampel dalam penelitian ini menggunakan metode simple random sampling. Penentuan jumlah sampel dengan menggunakan rumus Slovin (Putri \& Kartika, 2017) .

Keterangan:

$$
n=\frac{N}{1+N e^{2}}
$$

$\mathrm{n}=$ ukuran sampel

$\mathrm{N}=$ ukuran populasi

$\mathrm{e}=$ batas tolerasnsi kesalahan

Ditemukan sebanyak 54 mahasiswa untuk dijadikan sampel dalam penelitian ini.

Teknik pengumpulan data dalam penelitian ini adalah observasi dan angket. Observasi dilakukan untuk mengamati sejauh mana minat belajar mahasiswa pada mata kuliah matematika diskrit. Angket/kuisioner digunakan untuk pengumpulan data dari sejumlah responden (mahasiswa). Angket ini berupa pernyataan tentang pembelajaran daring dengan google classroom dan google meet serta minat belajar mahasiswa matematika diskrit. Angket mengunakan skala Likert 1 sampai 4, kemudian angket tersebut dibagikan kepada sampel (sebagian mahasiswa prodi Teknik Informatika tingkat 1 Universitas Nusantara PGRI Kediri) melalui google form.

Uji instrumen dalam penelitian ini menggunakan uji validitas dan uji reliabilitas untuk melihat suatu instrumen tersebut valid dan reliabel. Teknik analisis data dalam penelitian ini adalah regresi linear berganda (Multiple Regresion), uji hipotesisnya menggunakan uji $t$ dan uji f. Alat analisis data dalam penelitian ini menggunakan SPSS versi 23.

Variabel dalam penelitian ini meliputi variabel bebas dan variabel terikat. Variabel bebas terdiri dari 2 variabel yaitu variabel pertama pembelajaran daring dengan google classroom $\left(\mathrm{X}_{1}\right)$ dengan 3 indikator, variabel kedua pembelajaran daring dengan google meet $\left(\mathrm{X}_{2}\right)$ dengan 4 indikator. Variabel terikat dari penelitian ini adalah minat belajar (Y) dengan 4 indikator dan masing-masing indikator dari variabel bebas maupun terikat terdiri dari 2 item pernyataan. Indikator dari masing-masing variabel disajikan pada Tabel 1 .

Tabel 1 Indikator Angket

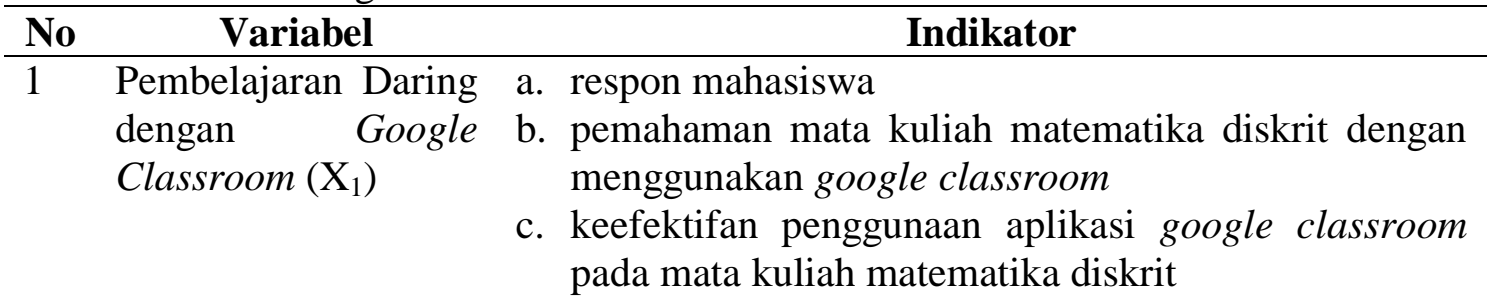

2 Pembelajaran Daring a. respon mahasiswa

dengan Google Meet b. pemahaman materi matematika diskrit menggunakan $\left(\mathrm{X}_{2}\right)$ google meet

c. keefektifan penggunaan google meet pada mata kuliah matematika diskrit

d. interaksi secara visual pada kuliah matematika diskrit 
DOI: $\underline{\text { https://doi.org/10.24127/ajpm.v10i2.3635 }}$

\begin{tabular}{|c|c|c|c|}
\hline No & Variab & & Indikator \\
\hline 3 & $\begin{array}{l}\text { Minat } \\
\text { Matematika } \\
\text { (Y) }\end{array}$ & $\begin{array}{l}\text { Belajar } \\
\text { Diskrit }\end{array}$ & $\begin{array}{l}\text { a. adanya perasaan senang terhadap mata kuliah } \\
\text { matematika diskrit } \\
\text { b. adanya pemusatan perhatian dan pikiran terhadap } \\
\text { matematika diskrit } \\
\text { c. adanya kemauan untuk belajar matematika diskrit } \\
\text { d. adanya kemauan dari dalam diri untuk aktif dalam } \\
\text { mengikuti perkuliahan matematika diskrit }\end{array}$ \\
\hline
\end{tabular}

HASIL DAN PEMBAHASAN

Dari hasil penelitian ini, dapat mengumpulkan data dari angket yang diisi oleh 54 mahasiswa yang telah ditentukan sebagai sampel. Kemudian data tersebut diolah dengan menggunakan SPSS 23 untuk melakukan uji validitas, uji reliabilitas dan uji regresi linier berganda.
Uji Validitas

Dari hasil angket,diperoleh hasil uji validitas yang diolah menggunakan SPSS 23 dan disajikan pada Tabel 2, Tabel 3 dan Tabel 4. Jika probabilitas korelasi lebih kecil atau kurang dari dari 0,05 , maka dinyatakan valid dan apabila hasil probabilitas korelasinya lebih besar dari 0,05 maka dinyatakan tidak valid (Potu, 2013).

Tabel 2 Validitas pembelajaran daring dengan google classroom $\left(\mathrm{X}_{1}\right)$

\begin{tabular}{lcccc}
\hline Variabel & Pernyataan no & Nilai Korelasi & Probabilitas Korelasi & Keterangan \\
\hline \multirow{2}{*}{ Pembelajaran } & 1 & 0,671 & 0,000 & Valid \\
daring dengan & 2 & 0,690 & 0,000 & Valid \\
google & 3 & 0,714 & 0,000 & Valid \\
classroom $\left(\mathrm{X}_{1}\right)$ & 4 & 0,812 & 0,000 & Valid \\
& 5 & 0,821 & 0,000 & Valid \\
& 6 & 0,748 & 0,000 & Valid \\
\hline
\end{tabular}

Tabel 2 menunjukan hasil uji validitas dari variabel pembelajaran daring dengan google classroom $\left(\mathrm{X}_{1}\right)$ yang terdiri dari 6 item pernyataan. Dari
Tabel 2 didapatkan bahwa pernyataan 1 sampai 6 dinyatakan valid karena probabilitas korelasi lebih kecil dari 0,05 .

Tabel 3 Validitas Pembelajaran Daring dengan Google Meet $\left(\mathrm{X}_{2}\right)$

\begin{tabular}{lcccc}
\hline \multicolumn{1}{c}{ Variabel } & Pernyataan no & Nilai Korelasi & Probabilitas Korelasi & Keterangan \\
\hline \multirow{3}{*}{ Pembelajaran } & 1 & 0,691 & 0,000 & Valid \\
daring dengan & 2 & 0,752 & 0,000 & Valid \\
google meet & 3 & 0,543 & 0,000 & Valid \\
$\left(\mathrm{X}_{2}\right)$ & 5 & 0,611 & 0,000 & Valid \\
& 6 & 0,492 & 0,000 & Valid \\
& 7 & 0,741 & 0,000 & Valid \\
& 8 & 0,663 & 0,000 & Valid \\
& 0,651 & 0,000 & Valid \\
\hline
\end{tabular}

Berdasarkan Tabel 3, dapat disimpulkan bahwa semua pernyataan sudah memenuhi kriteria valid karena probabilitas korelasi kurang dari 0,05. 
DOI: https://doi.org/10.24127/ajpm.v10i2.3635

Tabel 4. Minat belajar matematika diskrit (Y)

\begin{tabular}{lcccc}
\hline \multicolumn{1}{c}{ Variabel } & Pernyataan no & Nilai Korelasi & Probabilitas Korelasi & Keterangan \\
\hline & 1 & 0,593 & 0,000 & Valid \\
Minat & 2 & 0,558 & 0,000 & Valid \\
Belajar & 3 & 0,614 & 0,000 & Valid \\
Matematika & 4 & 0,727 & 0,000 & Valid \\
Diskrit (Y) & 5 & 0,807 & 0,000 & Valid \\
& 6 & 0,702 & 0,000 & Valid \\
& 7 & 0,821 & 0,000 & Valid \\
& 8 & 0,744 & 0,000 & Valid
\end{tabular}

Selanjutnya disajikan Tabel 4 yang merupakan hasil uji validitas dari variabel minat belajar matematika diskrit (Y) yang terdiri dari 8 item pernyataan. Dari tabel 4 didapatkan bahwa pernyataan 1 sampai 8 dinyatakan valid karena probabilitas korelasi lebih kecil dari 0,05.

Karena semua item dari variabel bebas maupun variabel terikat dinyatakan valid, maka dilanjutkan dengan uji reliabilitas. Apabila besarnya nilai Cronbach's Alpha yang diperoleh $>0,70$ maka instrument tersebut dikatakan reliabel. Seperti yang dikemukakan oleh (Riyadi \& Mulyapradana, 2017) bahwa suatu variabel dikatakan reliabel jika memberikan nilai Cronbach Alpha > 0,7. Hasil dari uji reliabilitas dari variabel bebas dan terikat, disajikan pada Tabel 5.

Tabel 5 Hasil uji reliabilitas

\begin{tabular}{lccc}
\hline Variabel & Jumlah item & Cronbach's Alpha & Keterangan \\
\hline Google Classroom $\left(\mathrm{X}_{1}\right)$ & 6 & 0,839 & Reliabel \\
Google Meet $\left(\mathrm{X}_{2}\right)$ & 8 & 0,803 & Reliabel \\
Minat Belajar Matematika Diskrit $(\mathrm{Y})$ & 8 & 0,848 & Reliabel \\
\hline
\end{tabular}

Pada Tabel 5 hasil uji Reliabilitas menunjukkan bahwa Pembelajaran Daring dengan Google Classroom $\left(\mathrm{X}_{1}\right)$, Pembelajaran Daring dengan Google Meet $\left(\mathrm{X}_{2}\right)$ dan Minat Belajar Matematika Diskrit (Y) memperoleh hasil Cronbach's Alpha > 0,70 sehingga ketiga variabel tersebut reliabel dan layak untuk dilakukan uji regresi berganda. Hasil uji regresi berganda disajikan pada Tabel 6.

Tabel 6 Hasil regresi berganda

\begin{tabular}{llllll}
\hline Variabel & Koefisien Regresi $(\beta)$ & $\mathrm{T}_{\text {hitung }}$ & $\mathrm{T}_{\text {tabel }}$ & Nilai Sig & Keterangan \\
\hline Konstanta & 13,509 & & & & \\
Google Classroom & 1,354 & 5,717 & 2,007 & 0,000 & $\mathrm{H}_{1}:$ diterima \\
Google Meet & $-0,540$ & $-2,585$ & 2,007 & 0,013 & $\mathrm{H}_{2}:$ diterima \\
$\mathrm{F}_{\text {hitung }}$ & 31.688 & & & 0,000 & $\mathrm{H}_{3}$ : diterima \\
$\mathrm{F}_{\text {tabel }}$ & 3,18 & & & & \\
$\mathrm{R}$ & 0,744 & & & & \\
$\mathrm{R}$ square & 0,554 & & & & \\
\hline
\end{tabular}


Dari Tabel 6 menunjukkan bahwa persamaan regresi yang didapat adalah $Y=13,509+1,354 X_{1}+-0,504 X_{2}$.

Kemudian nilai konstanta sebesar 13,509 mempunyai arti yaitu apabila nilai pembelajaran daring dengan google classroom $\left(\mathrm{X}_{1}\right)$ dan pembelajaran daring dengan google meet $\left(\mathrm{X}_{2}\right)$ sama dengan 0 , maka minat belajar (Y) dipengaruhi variabel selain pembelajaran daring dengan google classroom $\left(\mathrm{X}_{1}\right)$ dan pembelajaran daring dengan google meet $\left(\mathrm{X}_{2}\right)$ sebesar 13,509 atau minat belajar (Y) dipengaruhi oleh variabel lain di luar penelitian ini.

Nilai $\beta_{1}=1,354$ merupakan koefisien arah variabel pembelajaran daring dengan google calssroom $\left(\mathrm{X}_{1}\right)$ yang mempengaruhi minat belajar matematika diskrit (Y). Koefisien regresi $\beta_{1}$ didapatkan nilai sebesar 1,354 dengan tanda positif, dapat disimpulkan bahwa apabila variabel pembelajaran daring dengan google classroom $\left(\mathrm{X}_{1}\right)$ berubah satu satuan maka minat belajar matematika diskrit (Y) akan naik sebesar 1,354 dengan asumsi pembelajaran daring dengan google meet $\left(\mathrm{X}_{2}\right)$ mempunyai nilai sama dengan nol.

Nilai $\beta_{2}=-0,540$ merupakan koefisien arah variabel pembelajaran daring dengan google meet $\left(\mathrm{X}_{2}\right)$ yang mempengaruhi minat belajar matematika diskrit (Y). Koefisien regresi $\left(\beta_{2}\right)$ sebesar $-0,540$ dengan tanda negatif dapat disimpulkan bahwa apabila variabel pembelajaran daring dengan google meet $\left(\mathrm{X}_{2}\right)$ berubah satu satuan maka minat belajar pada matematika diskrit (Y) akan turun sebesar -0,540 dengan asumsi pembelajaran daring dengan google classroom $\left(\mathrm{X}_{1}\right)$ mempunyai nilai sama dengan nol.

Besarnya hubungan variabel pembelajaran daring dengan google Classroom dan pembelajaran daring dengan google meet terhadap minat belajar matematika diskrit sebesar 0,744 yang ditunjukkan pada nilai $\mathrm{R}=0,744$. Sedangkan Rsquare sebesar 0,554 atau $55 \%$ ini adalah besaran pengaruh variabel pembelajaran daring dengan google calssroom $\left(\mathrm{X}_{1}\right)$ dan variabel pembelajaran daring dengan google meet $\left(\mathrm{X}_{2}\right)$ terhadap minat belajar matematika diskrit (Y) sedangkan sisanya $45 \%$ variabel minat belajar matematika diskrit (Y) dipengaruhi oleh variabel lain diluar penelitian.

$\mathrm{H}_{1}$ adalah diduga pembelajaran daring dengan google classroom $\left(\mathrm{X}_{1}\right)$ mempunyai pengaruh terhadap minat belajar matematika diskrit (Y) sebesar 1,354 dengan nilai $t_{\text {hitung }}-5,717<t_{\text {tabel }}$ $2,007>5,717$ dengan nilai signifikan sebesar $0,000<0,05$ sehingga $\mathrm{H}_{1}$ diterima.

$\mathrm{H}_{2}$ adalah diduga pembelajaran daring dengan google meet $\left(\mathrm{X}_{2}\right)$ mempunyai pengaruh terhadap minat belajar matematika diskrit (Y) sebesar 0,540 dengan nilai $t_{\text {hitung }}-2,585<\mathrm{t}_{\text {tabel }}$ 2,007> 2,585 dengan nilai sig sebesar $0,013<0,05$ sehingga $\mathrm{H}_{2}$ diterima.

$\mathrm{H}_{3}$ adalah diduga pembelajaran daring dengan google classroom $\left(\mathrm{X}_{1}\right)$ dan pembelajaran daring dengan google meet $\left(\mathrm{X}_{2}\right)$ bersama-sama mempunyai pengaruh terhadap minat belajar 
matematika diskrit (Y) sebesar 0,554 dengan nilai $\mathrm{F}_{\text {hitung }}-31,688<\mathrm{F}_{\text {tabel }} 3,18$ $>31,688$ dengan nilai sig sebesar 0,000 $<0,05$ sehingga $\mathrm{H}_{3}$ diterima.

Dari hasil $\mathrm{H}_{1}$ menunjukkan bahwa besaran pengaruh pada pembelajaran daring dengan google classroom $\left(\mathrm{X}_{1}\right)$ terhadap minat belajar matematika diskrit $(\mathrm{Y})$ sebesar 1,354. Artinya, minat belajar mahasiswa pada mata kuliah matematika diskrit (Y) cenderung positif jika pembelajaran daring dilakukan melalui google classroom.

Sedangkan, dari hasil $\mathrm{H}_{2}$ menunjukkan bahwa besaran pengaruh pembelajaran daring dengan google meet $\left(\mathrm{X}_{2}\right)$ terhadap minat belajar matematika diskrit (Y) sebesar $-0,540$ yang berarti bahwa pembelajaran daring dengan google meet $\left(\mathrm{X}_{2}\right)$ cenderung mempunyai pengaruh negatif terhadap minat belajar matematika diskrit (Y).

$\mathrm{H}_{3}$ menunjukkan nilai Rsquare sebesar 0,554 mempunyai arti bahwa pembelajaran daring dengan google classroom $\left(\mathrm{X}_{1}\right)$ dan pembelajaran daring dengan google meet $\left(\mathrm{X}_{2}\right)$ secara bersama-sama mempunyai pengaruh sebesar 55\% terhadap minat belajar matematika diskrit (Y), sedangkan sisanya $45 \%$ dipengaruhi oleh variabel di luar penelitian ini.

Dari hasil yang sudah ditemukan, dapat diinterprestasikan bahwa pembelajaran daring dengan google classroom dan google meet berpengaruh terhadap minat belajar mahasiswa pada mata kuliah matematika diskrit. Hal ini sejalan dengan penelitian yang dilakukan oleh (Jusmawati et al., 2020) dengan hasil penelitian bahwa terdapat pengaruh pembelajaran berbasis daring terhadap minat belajar matematika mahasiswa Prodi PGSD Universitas Megarezky. Penelitian ini juga sejalan dengan penelitian yang dilakukan oleh (Jamil \& Aprilisanda, 2020) bahwa perkuliahan daring berpengaruh signifikan terhadap minat belajar mahasiswa dan penelitian yang dilakukan oleh (Yunitasari \& Hanifah, 2020) bahwa pembelajaran daring pada masa pandemi COVID-19 sangat berpengaruh terhadap minat belajar siswa.

Pembelajaran daring dengan menggunakan google classroom dan google meet berpengaruh positif dan negatif terhadap minat belajar matematika diskrit. Pada pembelajaran daring dengan google classroom cenderung berpengaruh positif terhadap minat belajar matematika diskrit, hal ini dikarenakan materi matematika diskrit yang diberikan melalui google classroom dapat diakses setiap waktu dan dimana saja tanpa ada batasan waktu tertentu, sehingga mahasiswa cenderung lebih menyukai pembelajaran daring dengan google classroom $\left(\mathrm{X}_{1}\right)$ daripada model pembelajaran daring yang lain. Seperti penelitian yang pernah dilakukan oleh (Sulistyowati et al., 2020) bahwa keunggulan pembelajaran daring yaitu pembelajaran atau perkuliahan dapat berjalan dengan baik, sesuai yang diharapkan, praktis sehinga perkuliahan dapat dilaksanakan secara fleksibel.

Pada pembelajaran daring dengan google meet cenderung berpengaruh negatif terhadap minat belajar 
matematika diskrit, hal ini dikarenakan pembelajaran daring dengan google meet $\left(\mathrm{X}_{2}\right)$ mempunyai beberapa kelemahan diantaranya mempunyai batas waktu tertentu, kuota data yang diserap lebih besar, harus mempunyai jaringan internet yang stabil, sehingga mahasiswa yang rumahnya berada di luar jangkauan internet akan kesulitan dalam mengikuti pembelajaran daring dengan google meet $\left(\mathrm{X}_{2}\right)$. Sebagaimana penelitian yang dilakukan oleh (Sulistyowati et al., 2020) memberikan hasil bahwa kendala yang dialami pada pembelajaran daring yaitu masalah koneksi internet dan kuota mahasiswa.

Dari hasil tersebut, dapat dilihat bahwa minat belajar matematika diskrit (Y) mahasiswa lebih besar jika pembelajaran daring dilakukan dengan google classroom $\left(\mathrm{X}_{1}\right)$ daripada pembelajaran daring dengan google meet $\left(\mathrm{X}_{2}\right)$. Dampak dari penelitian ini yaitu dapat melihat seberapa besar minat belajar dan antusias mahasiswa dalam mengikuti perkuliahan matematika diskrit jika pembelajaran dilakukan secara daring dengan menggunakan google classroom dan google meet. Selain itu, juga dapat dilihat minat belajar mahasiswa pada mata kuliah matematika diskrit lebih cenderung besar jika pembelajaran daring dilakukan menggunakan google classroom dari pada google meet.

\section{KESIMPULAN DAN SARAN}

Dari penelitian ini dapat disimpulkan bahwa 1) terdapat pengaruh pembelajaran daring dengan google classroom terhadap minat belajar mahasiswa pada mata kuliah matematika diskrit, 2) terdapat pengaruh pembelajaran daring dengan google meet terhadap minat belajar mahasiswa pada mata kuliah matematika diskrit, 3) terdapat pengaruh pembelajaran daring dengan google classroom dan google meet secara bersama-sama terhadap minat belajar mahasiswa pada mata kuliah matematika diskrit.

Saran untuk penelitian selanjutnya adalah penelitian ini diharapkan dapat menjadi referensi untuk peneliti selanjutnya yang berkaitan dengan metode pembelajaran daring.

\section{DAFTAR PUSTAKA}

Friantini, R. N., \& Winata, R. (2019). Analisis Minat Belajar pada Pembelajaran Matematika. JPMI (Jurnal Pendidikan Matematika Indonesia), 4(1), 6-11. https://doi.org/10.26737/jpmi.v4i1 .870

Jamil, S. H., \& Aprilisanda, I. D. (2020). Pengaruh Pembelajaran Daring Terhadap Minat Belajar Mahasiswa Pada Masa Pandemik Covid-19. Behavioral Accounting Journal, 3(1), 37-46. https://doi.org/10.33005/baj.v3i1. 57

Jusmawati, J., Satriawati, S., \& Sabilah, B. (2020). Pengaruh Pembelajaran Berbasis Daring Terhadap Minat. Jurnal Kajian Pendidikan Dasar, 5(2).106-111

Kurniawan, D. E. (2021). Pengaruh Metode Pembelajaran Daring Terhadap Minat Belajar 
DOI: https://doi.org/10.24127/ajpm.v10i2.3635

Mahasiswa di Masa Pandemi COVID-19. Jurnal Education and Development, 9(2), 47-51.

Lestari, I. (2014). Pengaruh Waktu Belajar Dan Minat Belajar. Jurnal Formatif, 3(2), 115-125.

Muhammad, I. (2020). Pengaruh Perkuliahan Daring Terhadap Kemandirian Belajar Mahasiswa Prodi Pendidikan Matematika Universitas Malikussaleh. Jurnal Ilmiah Pendidikan Matematika Al Qalasadi, 4(1), 24-30. https://doi.org/10.32505/qalasadi. v4i1.1567

Muhati, O., Wenas, J. R., Runtu, P. V. J., Matematika, P., Matematika, F., Alam, P., \& Manado, U. N. (2021). Pengaruh Model Pembelajaran Inkuiri Terbimbing Berbantuan Google Meet Terhadap Hasil Belajar Matematika Siswa Bahasan Aljabar. 2(1), 1-4.

Potu, A. (2013). Kepemimpinan, Motivasi, Dan Lingkungan Kerja Pengaruhnya Terhadap Kinerja Karyawan Pada Kanwil Ditjen Kekayaan Negara Suluttenggo Dan Maluku Utara Di Manado. Jurnal Riset Ekonomi, Manajemen, Bisnis Dan Akuntansi, 1(4), 1208-1218. https://doi.org/10.35794/emba.v1i 4.2894

Putri, B. S., \& Kartika, L. (2017). Pengaruh Kualitas Pelayanan Bpjs Kesehatan Terhadap Kepuasan Pengguna Perspektif Dokter Rumah Sakit Hermina Bogor.
Jurnal Riset Manajemen Dan Bisnis (JRMB) Fakultas Ekonomi UNIAT, 2(1), 1-12. https://doi.org/10.36226/jrmb.v2i1 .24

Rahmanto, M. A., \& Bunyamin. (2020). Efektivitas Media Pembelajaran Daring Melalui Google Classroom. Jurnal Pendidikan Islam, 11(November), 119-135.

Riyadi, S., \& Mulyapradana, A. (2017). Pengaruh Motivasi Kerja Terhadap Kinerja Guru Radhatul Atfal di Kota Pekalongan. Jurnal Litbang Kota Pekalongan, 13, 106-117.

Sijabat, A., Sianipar, H. S., \& Siahaan, T. M. (2020). Pengaruh Pembelajaran Daring Terhadap Minat Belajar Mahasiswa Pendidikan Fisika Uhkbpnp Pada Matakuliah Fisika Umum. Litpam, 84-88.

Suhada, I., Kurniati, T., Pramadi, A., Listiawati, M., Biologi, P. P., Gunung, S., \& Bandung, D. (2020). Pembelajaran Daring Berbasis Google Classroom Mahasiswa Pendidikan Biologi Pada Masa Wabah Covid-19. Digital Library UIN Sunan Gunung Jati, 2019, 1-9. http://digilib.uinsgd.ac.id/30584/

Sulistyowati, E., Rohmah, S. N., \& Haryadi, A. R. (2020). Pengaruh Covid-19 terhadap Minat Belajar Daring Mahasiswa. Jurnal Bismak, 1(1), 68-73. 
DOI: https://doi.org/10.24127/ajpm.v10i2.3635

Wiratama, N. A. (2020). Penerapan Google Meet Dalam Perkuliahan Daring Mahasiswa PGSD Pada Mata Kuliah Konsep Dasar PKN SD Saat Pandemi COVID 19. Jtiee, 4(2), 1-8.

Yanti, M. T., Kuntarto, E., \& Kurniawan, A. R. (2020). Pemanfaatan Portal Rumah Belajar Kemendikbud Sebagai Model Pembelajaran Daring Di Sekolah Dasar. Adi Widya Jurnal Pendidikan Dasar, 10(1), 61-68.

Yunitasari, R., \& Hanifah, U. (2020). Pengaruh Pembelajaran Daring terhadap Minat Belajar Siswa pada Masa COVID 19. Edukatif: Jurnal Ilmu Pendidikan, 2(3), 236-240. 